\title{
In Search of Rare Forest Primates in Nigeria
}

\author{
John F. Oates
}

Cercopithecus erythrogaster in University of Ibadan Zoo.

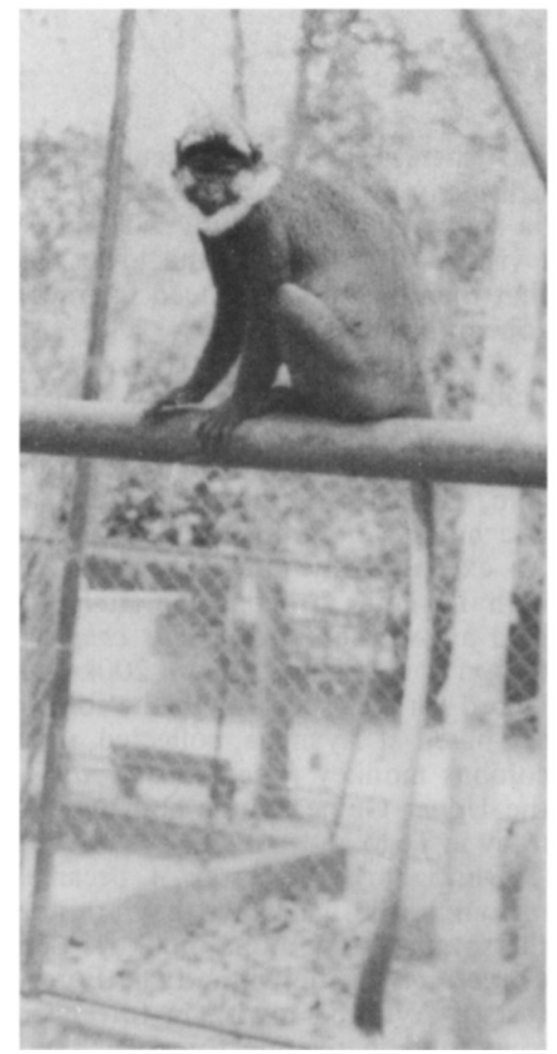

When the author visited Nigeria in 1981 to look at forests on the lower Niger, there had been no reports for 15 years of the red-bellied guenon Cercopithecus erythrogaster, and only a single specimen of the olive colobus Procolobus verus was known from the country. He found surviving populations of both monkeys, but each is threatened by widespread, intensive hunting, and by habitat destruction. If effective measures are not taken to protect the guenon and its rainforest habitat, this species could become extinct, since it occurs only in southwestern Nigeria.

Nigeria has a rich primate fauna. Twenty-one species have been recorded, a number matched in few other African states. ${ }^{5}$ This richness is partly the result of a diversity of ecosystems, including large areas of coastal swamp, inland rain forest, and savanna, together with montane grassland and forest along the eastern border with Cameroun. Also, in Nigeria elements of the Upper Guinea forest community, centred to the west in Liberia, meet elements of the CamerounGabon community. Consequently, Nigeria's primate fauna is a unique mix of species from forest and savanna, and from east and west. One species, Cercopithecus erythrogaster, is known only from Nigeria.

Despite their interest, Nigeria's primates have been little studied by field biologists. This is largely due to the high density of people, particularly in the southern forest zone, where 'bushmeat' is a major food item. Hunting and habitat destruction have made the larger forest primates rare in accessible areas, 
and where primates still occur, they are usually very shy. Nevertheless, there are still many intriguing problems, particularly relating to zoogeography, that could be answered by field studies. To investigate the possibilities for future field work I visited the forests of the lower Niger in January 1981. This visit made clear that there is a pressing need for more effective wildlife protection in the forest zone of Nigeria.

\section{Benue State}

I went first to the town of Ayangba in the angle of the Niger and Benue Rivers, in the part of Benue where Igala-speaking people live, sometimes called Igalaland. This is at the northern boundary of the rain-forest zone and its vegetation is a mosaic of farmland, Guinea savanna, relict high forest and riverine forest. An exceptionally interesting area for primates, I had visited it briefly in 1966 with Dr Peter Jewell while studying prosimian primates. Here we had seen a wild angwantibo Arctocebus calabarensis, a typical member of the CamerounGabon forest fauna, about $200 \mathrm{~km}$ north of the previous most north-westerly record for this species. ${ }^{4}$ In the following year Paul Gross, an American missionary based at Ayangba, collected, in the same area, a single specimen of the olive colobus monkey Procolobus verus, ${ }^{2}$ usually considered to be characteristic of the Upper Guinea fauna and until 1967 not known further east than $750 \mathrm{~km}$ away in Togo.

During my 1981 stay it became evident that, although primates are now uncommon in Igalaland, they are not as rare as in densely-populated Iboland to the south. ${ }^{3}$ I saw mona monkeys Cercopithecus mona and putty-nosed guenons C. nictitans in the Okura-Iyale Forest Reserve (a high forest relict $10 \mathrm{~km}$ northeast of Ayangba town), in forest fringing the Okura River $20 \mathrm{~km}$ south of the town, and in riverine forest on the south bank of the Benue close to its confluence with the Niger. Monas seemed to be more abundant than putty-noses; I saw at least eight different social groups of mona, compared with five puttynose groups, all with more individuals than the putty-nose groups. On 17 January I saw an additional three groups of mona on the north bank of the Benue near Mozum, the first record of this species from north of the river. Olive colobus are probably rare in Igalaland today. My only definite sighting of these pale, slender colobines was on 13 January when I saw four in a mixed party with monas and putty-noses in the $200 \mathrm{~m}$-wide strip of seasonally-flooded forest along the Okura River. The river runs through what is regarded as a tsetse area that only became easily accessible after a road was built in 1978 .

Although the Okura River forest is still relatively undisturbed, agricultural and economic development, and the rapid growth of the human population of Igalaland, are putting great pressures on most remaining forests. There have been increases both in the rate of conversion of forest to farmland outside govern. ment reserves, and in the rate of felling within reserves. Hunting of the larger mammals has also increased greatly, and is essentially uncontrolled even in forest reserves. It has been encouraged by the wide availability of shotguns, the high cost of meat, and the movement of other people into an area inhabited predominantly by Muslims, who traditionally have not eaten monkeys. Today, smoked monkey carcases sell for about 10 naira (approximately $£ 8$, or $\$ 16$ ) in the Ayangba market. As a result, most of the monkeys I saw were very shy and fled rapidly when approached.

Paul Gross, who has spent most of his life in Igalaland, told me that green 


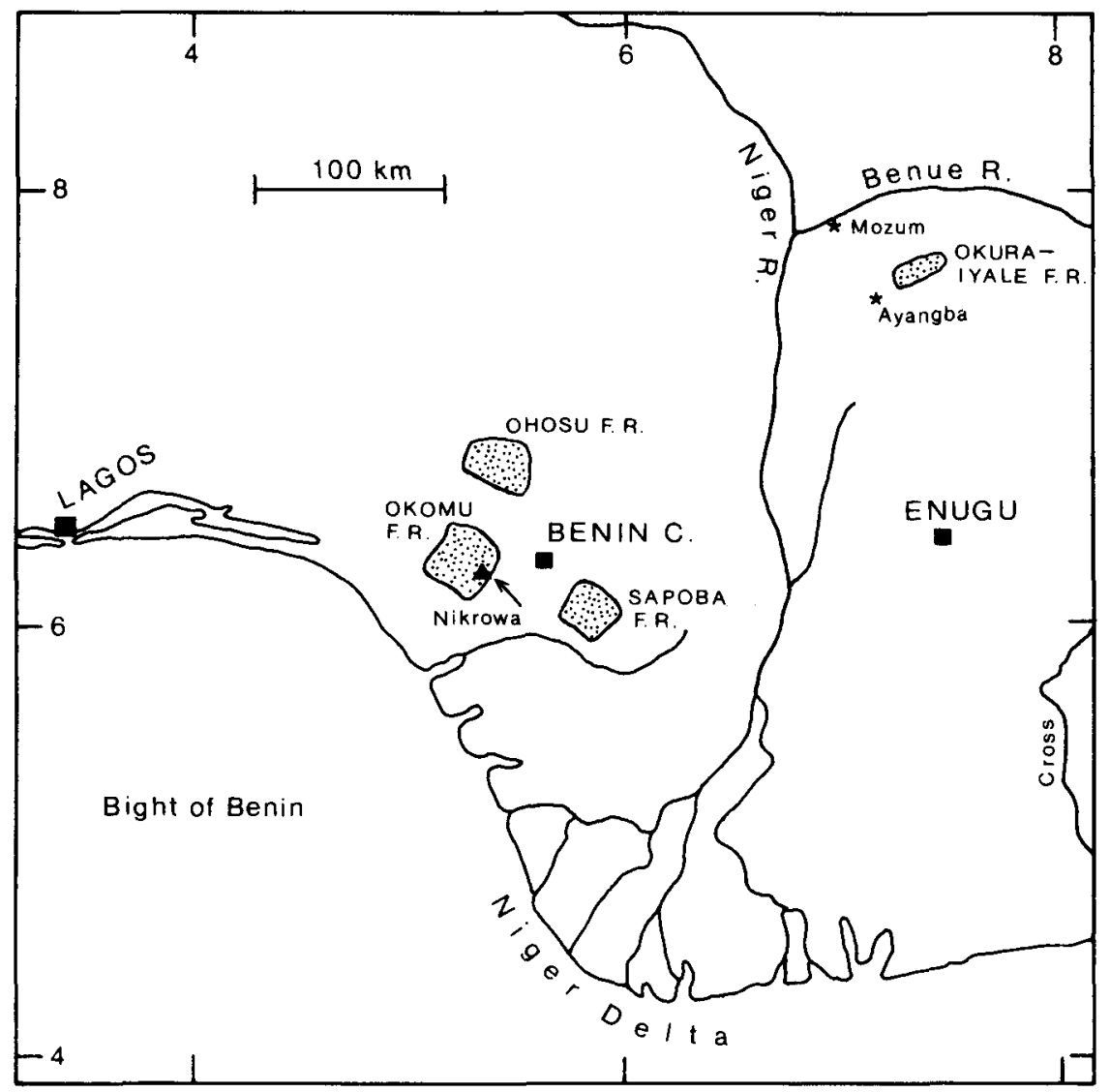

monkeys, baboons and patas monkeys used to be common, and that red-crowned mangabeys Cercocebus $t$. torquatus occurred in small numbers. I saw none of these animals during my visit, although I did see some prosimian primates, which do not seem to be hunted significantly. Using a battery-powered headlamp, I observed several angwantibos in the Okura-Iyale Reserve, and some dwarf galagos Galago demidovii. These species are currently less threatened than the monkeys, but the destruction of their habitats must make their future prospects uncertain.

\section{Bendel State}

After visiting Igalaland I went west across the Niger to Bendel State. Olive colobus have never been reported from this side of the river, although they would be expected to occur there. I wanted to find out if anyone knew of their existence in Bendel, and I also wanted to gather any information I could about the mysterious red-bellied guenon Cercopithecus erythrogaster.

First described by J.E. Gray in 1866 on the basis of a juvenile female from the London Zoo that had probably been shipped from Lagos, the type specimen was distinguished from other small Cercopithecus species by a unique combination of pelage features, including a light reddish-brown belly, a ruff of white hair under the lower jaw (resembling that of $C$. lhoest $i$ ) and a triangle of gold-tipped hairs on the anterior part of an otherwise black crown. No more than ten speci- 
mens entered museum collections over the next 70 years, all from menageries; the wild population from which they came remained completely unknown until 1938, when P.F. Mason collected a small monkey in the Ohosu Forest Reserve, about $60 \mathrm{~km}$ north-west of Benin City. The following year, Mason collected three more in Ohosu; in an article in the Nigerian Field ${ }^{1}$ he referred to it as 'Spot-nosed Monkey No. 2'. 'These olive-grey monkeys were seldom seen,' he reported, 'although they travel in troops of fifteen or twenty in number. They do not appear to be restricted to high forest as I have seen them in secondary bush and old farmland, although in these cases areas of high forest were never very far away.'

Mason sent his specimens to D.R. Rosevear, who identified them as C. erythrogaster. In 1947, Rosevear himself collected two additional specimens, one from Nikrowa in the Okomu Forest Reserve, $30 \mathrm{~km}$ west of Benin, and one from the Sapoba Forest Reserve, $40 \mathrm{~km}$ south-east of the city. All six specimens entered the collection of the British Museum (Natural History) in 1950. Apart from a single specimen in the US National Museum collected in Sapoba in 1966, the handful of specimens that have entered museum collections since 1938 have all come from zoos and medical research laboratories. Although its geographical range may be greater, the proven distribution of the species is therefore limited to the rain-forest zone of Nigeria within a $60 \mathrm{~km}$ radius of Benin City - the most restricted range of any Cercopithecus.

The skins of wild-collected examples of this guenon share with all the menagerie specimens a distinct white throat ruff and golden crown, but they lack the red belly of the type and a few other specimens. The significance of this variation remains unclear.* Some museum skins have white hairs on the nose, but most have brown or black noses, and none that I have seen has a distinct nose spot.

When I arrived in Bendel, I wondered if anything more would ever be learned about erythrogaster. Apart from Mason's notes, there was a complete lack of information on its natural history and, as far as I knew, it had not been seen for 15 years. It was quite possibly extinct. But, the day after my arrival in Benin I was excited to find in the Ogba Zoo two female erythrogaster caged with a putty-nosed guenon and labelled as olive colobus monkeys! Their appearance corresponded closely to skins I had seen in European museums. Both had dark noses, and one had a scattering of red-tipped hairs on its belly and reddish coloration on the inner sides of its limbs. The cage label indicated that the monkeys had come from Ide, a village near Ohosu.

Next day (22 January) I travelled with Dr Pius Anadu of the University of Benin to Nikrowa, on the Osse River in the Okomu Forest Reserve, from where one of Rosevear's specimens had come. There are pockets of cultivation in the reserve, which covers some $1200 \mathrm{sq} \mathrm{km}$, and the rest of it is being exploited for timber; most big trees have already been felled. Near Nikrowa, where there is a large lumber camp, we walked for a short distance in the forest but we neither saw nor heard any sign of monkeys.

Next morning I took a motor-canoe $15 \mathrm{~km}$ up-river to Ikoro. The river's east bank, which is outside the reserve, is quite heavily settled, and many people were travelling on the waterway, fishing in it, and collecting 'wine' from the numerous

\footnotetext{
* Since most known examples do not have red bellies, 'red-bellied guenon' is an inappropriate name for the species. Rosevear's 'white-throated guenon' would be more suitable. 'Ekhokko' is the local, Bini, name for the species.
} 
Raffia palms along its banks. The least disturbed stretch lay half-way between Nikrowa and Ikoro, and here, paddling quietly, I had three encounters with monkeys. The first encounter was with at least five animals, including at least one $C$. erythrogaster, the second was with a single erythrogaster, clearly seen and probably an adult male, and the third was with several animals resembling erythrogaster of which I was unable to get a clear view. All were very shy and fled rapidly when detected, without calling. In each case they were first seen at a height of 3-10 $\mathrm{m}$ in the dense tangle of small trees and climbing plants bordering the river. Many scattered trees emerged through this low tangle, some of them to at least $30 \mathrm{~m}$, but most not more than $20 \mathrm{~m}$ high.

I am sure that there is a great deal of hunting in the Nikrowa area, both by people based at the lumber camp, and by villagers living along the edge of the reserve. I saw three recently-killed Maxwell's duikers Cephalophus maxwelli in the parts of two days I spent at Nikrowa, and heard gunshots in the forest at night. However, despite habitat destruction and hunting, the red-bellied guenon obviously still survives in the wild. Much more extensive survey work is needed to determine its range and status.

I obtained no direct evidence of other primates surviving in the Benin area, apart from hearing the double-boom and hack of Cercopithecus mona close to one of the erythrogaster sightings at Nikrowa, and seeing several Galago demidovii in the Okomu Forest at night. However, Ogba Zoo has specimens of $C$. nictitans and Cercocebus torquatus, both of which were recorded from Ohosu over 40 years ago. No-one I met in Bendel was familiar with an animal corresponding to a description of the olive colobus, but this is not convincing evidence that the species is absent, for the olive colobus is very cryptic in its appearance and habits.

On the basis of one animal that came to the London Zoo from Benin at the beginning of this century, Sclater's guenon Cercopithecus erythrotis sclateri has been considered to occur sympatrically with erythrogaster west of the Niger. Since all the known wild-collected specimens of this species are from east of the Niger, and the provenance of captive animals is notoriously hard to establish, it seems unlikely that Sclater's guenon lives, or has lived, in Bendel. Again, more survey work is needed to confirm this.

\section{Recommendations}

First, I recommend that $C$. erythrogaster should be listed in the Red Data Book and in Appendix I of CITES. It must be a threatened species, given its restricted range, and the pressures on surviving populations from hunting and habitat destruction.

Second, a search should be made for other zoo specimens of erythrogaster, in addition to those at Ogba. A captive breeding programme could be valuable.

Third, more extensive survey work is needed to establish the distribution and status of surviving rain-forest primates in Nigeria. Attention should focus on the endemic $C$. erythrogaster.

The Nigerian Government, while promoting agricultural development, seems also to be enthusiastic about creating new game reserves and national parks. If such reserves are to be fully effective, they must be created on the basis of sound information about present day animal populations, and part of their purpose should be to protect unique faunal elements and ecosystems. Primate surveys should therefore aim to identify those forest areas where species such as 
C. erythrogaster can be given most effective protection. Not only will priorities have to be established in terms of which areas to protect, but special recommendations will also have to be made on the control of hunting and on other serious practical difficulties. Although the effective conservation of Nigeria's forest wildlife will not be easy, if it is not attempted, an irreplaceable resource will be lost.

\section{POSTSCRIPT}

At the time of going to press the author was back in Nigeria to investigate more thoroughly the status of $C$. erythrogaster. To date he has located four more zoo specimens (three in Ibadan and one in Port Harcourt), although one of the two Ogba animals has died, and confirmed that a population survives in the Sapoba Forest Reserve.

\section{Acknowledgments}

I would particularly like to thank Paul Gross and his family for their hospitality in Ayangba and for helping me with many aspects of my Igalaland survey, and Dr P. A. Anadu for generous assistance in Bendel. For help and information, I also thank Dr Mark Eluwa at the University of Nigeria, H. Hvidberg-Hansen and other staff on the Ayangba Agricultural Development Project, Thaddeus Agbozele at the University of Benin, officials of the Bendel State Ministry of Agriculture and Natural Resources in both Benin City and Iguobazuwa, staff of African Timber and Plywood Co. at Nikrowa, and D. Brandon-Jones. My visit to Nigeria was partly supported by a grant from the Research Foundation of the City University of New York.

\section{References}

1. MASON, P.F. 1940. A brief faunal survey of north-western Benin. I. Mammals. Nigerian Field 9: 17-22.

2. MENZIES, J.I. 1970. An eastward extension to the known range of the olive colobus monkey (Colobus verus, Van Beneden). J.W. Afr. Sci. Assoc. 15: 83-4.

3. OATES, J.F. 1968. Wildlife of Biafra. Animals 11: 266-8.

4. OATES, J.F. and P.A. JEWELL. 1967. Westerly extent of the range of three African lorisoid primates. Nature 215: 778-9.

5. ROSEVEAR, D.R. 1953. Checklist and Atlas of Nigerian Mammals. Government Printer, Lagos.

This paper is Misc. Contribution No. 8 from the IUCN/SSC Primate Specialist Group.

John F. Oates, Department of Anthropology, Hunter College of CUNY, 695 Park Avenue, New York, NY 10021 , USA.

\section{Expedition Help}

If you are planning an expedition the Expedition Advisory Centre's 1982-83 programme may help. It includes courses and seminars ranging from planning a small expedition to expedition medicine and photography, and a Landrover driving course. The centre produces publications, keeps lists of planned expeditions, consultants, and members available for expeditions, and has a map collection and expedition report library. The Expedition Advisory Centre is at The Royal Geographical Society, 1 Kensington Gore, London SW7 2AR, UK. 